\title{
Complex role of connexin 43 in astrocytic tumors and possible promotion of glioma-associated epileptic discharge (Review)
}

\author{
HUI DONG, XING-WANG ZHOU, XIANG WANG, YUAN YANG, JIE-WEN LUO, YAN-HUI LIU and QING MAO \\ Department of Neurosurgery, West China Hospital, Sichuan University, Chengdu, Sichuan 610041, P.R. China
}

Received October 20, 2016; Accepted June 19, 2017

DOI: $10.3892 / \mathrm{mmr} .2017 .7618$

\begin{abstract}
Connexin (Cx)43 is a multifunction protein which forms gap junction channels and hemi-channels. It also contains abundant binding domains which possess the ability to interact with certain $\mathrm{Cx} 43$-associated proteins and therefore serve a fundamental role in various physiological and pathological functions. However, the understanding of the association between cancer and $\mathrm{Cx} 43$ along with $\mathrm{Cx} 43$-gap junctions (GJ) remains unclear. All available data illustrate that $\mathrm{Cx} 43$ and its associated GJ serve important functions in cancers. The expression levels of Cx43 demonstrate a downward trend and an increase in the levels of malignancy, particularly in astrocytomas. The GJ intercellular communication activity in glioma cells can be adjusted via Cx43 phosphorylation and through the combination of $\mathrm{Cx} 43$ and its associated protein. Available evidence reveals $\mathrm{Cx} 43$ as a tumor-inhibiting factor that suppresses glioma growth and proliferation. However, its mechanism is also regarded as complicated and ambiguous. Furthermore, it is apparent that Cx43-GJ and the carboxyl tail may contribute to glioma growth and proliferation too. However, this valuable role could be weakened by its effects on migration and invasiveness. The detailed mechanism remains unclear and full of controversies. Cx43 can enhance the motor ability and invasiveness of astrocytic glioma cells. It is also able to influence glioma cells to detach from the tumor core to the peritumoral neocortex. This peritumoral region has recently been regarded as the basic focus of glioma-associated seizure. Thus, Cx43 may take part in the onset and development of glioma-associated epileptic discharge. In addition, change and increase of $\mathrm{Cx} 43$ expression in GJs has been observed in seizure perilesional tissue, which is associated with brain tumors. $\mathrm{Cx} 43$ or $\mathrm{GJ} /$ hemi-channels exert enduring effects in the promotion of glioma-associated epileptic release through direct mass effects and change of the
\end{abstract}

Correspondence to: Professor Qing Mao, Department of Neurosurgery, West China Hospital, Sichuan University, 37 Guo Xue Xiang, Chengdu, Sichuan 610041, P.R. China

E-mail: maoqing@scu.edu.cn

Key words: connexin 43, glioma, proliferation, motility, invasiveness, glioma-associated epilepsy tumor microenvironment. However, there are still a number of issues concerning this aspect that require further exploration. $\mathrm{Cx} 43$, as a potential treatment target against this incurable disease and its common symptom of epilepsy, requires further investigation.

\section{Contents}

1. Introduction

2. Structure and function

3. Expression of $\mathrm{Cx} 43$ and glioma grade

4. Cx43 and glioma proliferation, invasion and migration

5. Cx43 may promote glioma-associated epileptic discharge

6. Facilitating disease diagnosis and therapy

7. Conclusion

\section{Introduction}

Glioma accounts for the majority of central nervous system (CNS) malignancies. They are difficult to cure and always present a poor prognosis. Histologically, glioma can be divided into four classes: Astrocytomas, oligodendrogliomas, ependymomas and mixed gliomas; diffuse gliomas are the most common. According to the 2007 World Health Organisation CNS tumor classification (1), CNS gliomas are diagnosed as grade II (diffuse astrocytoma, oligodendroglioma and oligoastrocytic tumors), grade III (anaplastic astrocytoma, oligodendroglioma and oligoastrocytic tumors) and grade IV (glioblastoma multiforme; GBM). The evidence is that high grade gliomas (III and IV) are the most common, and GBM occupies $30 \%$ of CNS gliomas (2). Although the therapeutic strategies of glioma involve continuous improvement and adjustment, the prognosis remains unsatisfactory. The Chinese Glioma Cooperative Group statistics (3) give a median general survival time (OS) of GBM at only 14.4 months, along with 5 -year OS rates at $9 \%$. Therefore, identification of the pathogenic mechanism of glioma is important, and novel therapeutic strategies to reduce the high mortality rates of CNS malignancies are required.

In the past, researchers have concentrated on exploring the molecular mechanism of glioma, which led to the discovery of isocitrate dehydrogenase 1 , telomerase reverse transcriptase and various other molecules. A CNS glioma molecular classification has been suggested (3-5). The present review aimed 
to focus on a widely-studied molecule, connexin (Cx)43, which is largely expressed in astrocytes and which participates in the construction of gap junctions (GJs) of astrocytes or astrocytes and neurons (6). Cx43 is a multifunctional protein which not only constructs gap junction channels and hemi-channels (7), but also contains numerous binding domains which can interrelate with various $\mathrm{Cx} 43$ linked proteins, thus serving an elemental role in several physiological and pathological functions (8). Cx43 has been reported to be involved in the inception of certain neurodegenerative diseases, including Alzheimer's and Parkinson's disease (9), epilepsy secondary to focal cortical dysplasia (FCD) (10) and amyotrophic lateral sclerosis (11), among others. The role of $\mathrm{Cx} 43$ in glioma has also been widely and consistently explored.

The present review aimed at introducing the role of $\mathrm{Cx} 43$ in glioma from the following aspects: i) Expression of $\mathrm{Cx} 43$ and glioma grade; ii) inhibition of glioma proliferation, but improvement in invasion and migration; iii) consideration of Cx43 and the possibility of its promoting glioma-associated epileptic discharge; and iv) disease diagnosis and therapy.

\section{Structure and function}

Cx43 is encoded by the GJA1 gene and is strongly expressed in astrocytes. Cx43 is an elemental membrane protein, which contains three intracellular regions, two extracellular loops together with multiple trans-membrane domains. The intracellular region is composed of $\mathrm{N}$ - and $\mathrm{C}$-terminal (CT) domains along with a loop that links the trans-membrane domains. Cx43CT comprises of amino acids 232-381, a plurality of binding-domains and phosphorylation sites (12). The present aimed to review the functions of $\mathrm{Cx} 43$ and specifically to its functions in constructing GJs. Astrocyte Cx43 gathers adjacent to the central pore and forms connexons. Subsequently, it is coupled with neighbouring astrocytes or neurons through apposing connexons to form GJ channels, which may directly exchange the cytoplasm between coupled astrocytes and permit swapping of ions together with certain small molecules. Astrocyte Cx43 may also form membrane hemi-channels, which are directly involved in material exchange between the extracellular milieu and astrocytes or neurons (13-15).

From its special structure and character (forming GJ channels and hemi-channels), $\mathrm{Cx} 43$ can therefore serve important physiological and pathological functions in CNS through these two routes.

GJ channels and hemi-channels. Cx43 is highly expressed in astrocytes, lasting until adulthood. In relation to neurons, the typical feature of astrocyte GJs is to support the astrocytes in couple formation. This involves ions, amino acids, metabolites and certain small molecules to exchange through the cytomembrane between astrocytes in addition to extracellular milieu (16). The principal roles of astrocyte GJs are described below.

Potassium spatial buffering. When neurons are in an energized state, a large number of $\mathrm{K}^{+}$ions efflux into the intercellular space. Aggregation of extracellular milieu $\mathrm{K}^{+}$ activates the inwardly rectifying $\mathrm{K}^{+}$channel, and there is an excessive intake of $\mathrm{K}^{+}$, rapidly dispersed to adjacent astrocytes or neurons through GJs. Ultimately, the $\mathrm{K}^{+}$homeostasis of this coupling is maintained and is considered to be beneficial in maintaining the normal microenvironment, in addition to the electrical activity of neurons (17).

Signal transduction. Mediated by $\mathrm{Cx} 43$, astrocytes form functional group coupling astrocytes networks which may contribute to long-range signal transduction. External stimulation can spread through astrocytes via calcium waves to participate in neuromodulation $(18,19)$. Astrocytes also contain an adenylate cycle and phosphoinositide courier delivery system, which can transmit signals through second messengers, including cyclic adenosine monophosphate (20).

Nutritional support. Astrocytes take in glucose which can be delivered to neurons through the GJ to contribute to metabolic regulation of neurons (21). Additionally, through the GJs formed by $\mathrm{Cx} 43$ between astrocytes and neurons, these two cell types may directly achieve material exchange along with signal transduction (22).

Specific binding domains and phosphorylation sites. Cx43 is a structurally complex protein in the C-terminal domains. There are certain binding domains which can interrelate with paired molecules to contribute to the building and regulation of cell architecture, polarity, mobility, invasion and growth $(8,12,23,24)$. According to the reviews put forward by Giepmans (8) and Tabernero et al (12), the interactions of Cx43 when closely associated with proteins are summarized in Table I.

\section{Expression of $\mathrm{Cx} 43$ and glioma grade}

In standard physiological states, Cx43 is prominently expressed in astrocytes. However, when the cell becomes malignant, the expression of $\mathrm{Cx} 43$ is downregulated. Thus, Sin et al (25) suggested that decreased Cx43 expression is accompanied by greater proliferation and malignancy of tumors. By studying the expression of $\mathrm{Cx} 43$ in human glioma and normal tissue microarray slides, mainly by western blot analysis and immunohistochemical staining, Sin et al (26) and Ye et al (27) noted a reduced expression of Cx43 in the tumor center as the glioma malignancy increased. Grade I and II primary astrocyte gliomas may express an enhanced immunoreactivity compared with normal brain tissue. However, it lacks the distinct disrupting staining of normal astrocytes. In high grade glioma, the expression of $\mathrm{Cx} 43$ is commonly reduced compared with normal tissues. It is also decreased in the majority of GBM, where the expression of $\mathrm{Cx} 43$ protein is insignificant $(12,26,27)$. However, Crespin et al (28) did not share this point of view. First, in spite of the modest inverse association between tumor grade and Cx43 expression, over half of glioblastomas still express Cx43. Secondly, the expression of $\mathrm{Cx} 43$ between grade II and III astrocytes gliomas is not significantly different. Additionally, the various expression levels of $\mathrm{Cx} 43$ between grade III astrocytoma and oligodendroglioma suggest that $\mathrm{Cx} 43$ can act as a marker in discriminating against grade III oligodendroglioma in addition to astrocytoma. In reality, expression of $\mathrm{Cx} 43$ differs within the same tumor. For instance, $\mathrm{Cx} 43$ is rarely labelled at the membranes and in the cytoplasm of GBM cells. Nevertheless, it is abundant at the plasma membrane of reactive astrocytes 
Table I. Cx43-interacting proteins.

\begin{tabular}{|c|c|c|c|}
\hline Protein and phosphorylation sites & Amino acids & Function & Cx43 interaction \\
\hline ZO-1 & $379-382$ & $\begin{array}{l}\text { Tight junctions, adherens } \\
\text { junctions, cytoskeleton } \\
\text { build, signal transduction }\end{array}$ & $\begin{array}{l}\text { Inversely regulates gap Junctional } \\
\text { communication and Hemichannel } \\
\text { activity, prevents cytoplasmic } \\
\text { localization and malignization }\end{array}$ \\
\hline Src & $\begin{array}{l}247,265 \\
274-283\end{array}$ & $\begin{array}{l}\text { Phosphorylates } \mathrm{Cx} 43 \\
\text { oncogenic activity }\end{array}$ & $\begin{array}{l}\text { Inhibits Cx } 43 \text {-based GJC, Tumor } \\
\text { suppression, but excludes the } \\
\text { C-terminal tail for ZO-1 binding }\end{array}$ \\
\hline Tubulin & $234-262$ & $\begin{array}{l}\text { Combines into dimers, } \\
\text { assembles microtubules }\end{array}$ & $\begin{array}{l}\text { Modulates cell polarity, Motility } \\
\text { and directional cell migration }\end{array}$ \\
\hline $\begin{array}{l}\text { Cadherins, } \\
\text { catenin and actin }\end{array}$ & & $\begin{array}{l}\text { Adherens junctions, } \\
\beta \text {-catenin modulates } \\
\text { Wnt-mediated gene } \\
\text { transcription }\end{array}$ & Modulate cell motility \\
\hline CK1, PKA & & Phosphorylates Cx43 & Upregulate Cx43 assembly \\
\hline MAPK, PKG, PKC & & & Inhibit Cx43-based GJC \\
\hline
\end{tabular}

$\mathrm{Cx}$, connexin; ZO, zonula occludens; CK, creatine kinase; PK, protein kinase; MAPK, mitogen-activated protein kinase; GJC, gap junction communication; Src, proto-oncogene tyrosine-protein kinase.

in the surrounding tumor mass $(26,28)$. The notable features of these areas are tumor cell infiltration and reactive astrocytes $(26,29)$. The peritumor cortex not infiltrated by glioma cells may increase $\mathrm{Cx} 43$ immunoreactivity and reactive astrocytes. However, this appearance is perhaps associated with the existence of epileptic seizures (30). Besides, this conclusion may not be valid; the origin of glioma associated seizure stemming from the peritumor area and infiltration by glioma cells has been widely accepted (31). Therefore, the above conclusion may require further elucidation. In addition, due to the driving factor of glioma pathogenesis partly being ascribed to cancer stem cells (CSCs), Hitomi et al (32) explored the expression levels of Cx43 in GBM glioma stem cells (GSCs). The results indicated that $\mathrm{Cx} 43$ is predominantly expressed in non-GSCs while Cx46 is expressed in CSCs. Yu et al (33) further identified lower expression of Cxs and the loss of GJ-like structures together with dysfunction of GJ intracellular function in GSCs.

\section{Cx43 and glioma proliferation, invasion and migration}

Glial tumors, as the most common supratentorial neoplasms, are particularly difficult to cure. This is made more difficult with a poor prognosis, largely due to tumor cell migration, invasion and proliferation. This section briefly introduces the role of Cx43 in glioma migration, invasion and proliferation in addition to its possible mechanism. Previous studies $(12,25,34,35)$ focused more on the association between $\mathrm{Cx} 43$ and cancer, including astrocytic glioma. However, more recent studies have proposed novel insights. The present review aimed to examine the association of $\mathrm{Cx} 43$ and astrocytic glioma in light of previous reviews and new findings.

Inhibition of glioma growth and proliferation. Thus far, the majority of studies have indicated that $\mathrm{Cx} 43$, as a tumor suppressor factor, inhibits astrocytoma growth and proliferation in a variety of ways. Treatments that regulate $\mathrm{Cx} 43$ expression, including tolbutamide (36,37), selective $\beta 2$-AR agonist (38), $17-\beta$ estradiol (E2) (39), ciliary neurotrophic factor (40) and low doses of $\gamma$-radiation (41) have been verified. $\mathrm{Cx} 43$ may therefore inhibit glioma growth and proliferation (Table II).

The specific mechanism of how $\mathrm{Cx} 43$ influences glioma proliferation remains to be elucidated. However, the following mechanisms may contribute to the regulation of $\mathrm{Cx} 43$ in glioma proliferation (Table II).

Affecting the GSC phenotype. GSCs are cells which possess the capability for self-renewal and are considered among the driving factors in glioma pathogenesis. Notably, $\mathrm{Cx} 43$ is mostly expressed in non-GSCs, and the expression of Cx43 in GSCs is low $(32,33)$. When reconstituting Cx43 in GSCs, the tumorigenicity of GSCs is inhibited, while self-renewal and proliferation are delayed. Yu et al (33) described the interaction of $\mathrm{Cx} 43$ with epithelial cadherin as having an influence on CSC phenotype through the Wnt/ $\beta$-Catenin signaling pathway; this may be a potential mechanism. Additionally, as a proto-oncogene, Scr and its interaction with $\mathrm{Cx} 43$ are also considered to be involved in glioma proliferation regulation. Tabernero et al (12) hypothesized c- proto-oncogene tyrosine-protein kinase (Src) inhibiting Src activity as the main initiator of $\mathrm{Cx} 43$. It has an effect on GSCs: Gangoso et al (42) transfected Cx43 to GSCs and identified that Ki-67-positive glioma cells decreased and expressed $\mathrm{Cx} 43$, while downregulating DNA-binding protein inhibitor (a transcriptional regulator) expression via inhibition of Src activity. Consequently, there was reduced (sex determining region Y)-box (Sox2) expression, downregulation of Sox 2 and a reduction in GSC self-renewal (Fig. 1).

Intervention in cell metabolism. Cancer cells detect rapid proliferation by adapting to metabolic environmental changes. For glioblastoma, uptake of enough glucose or the 


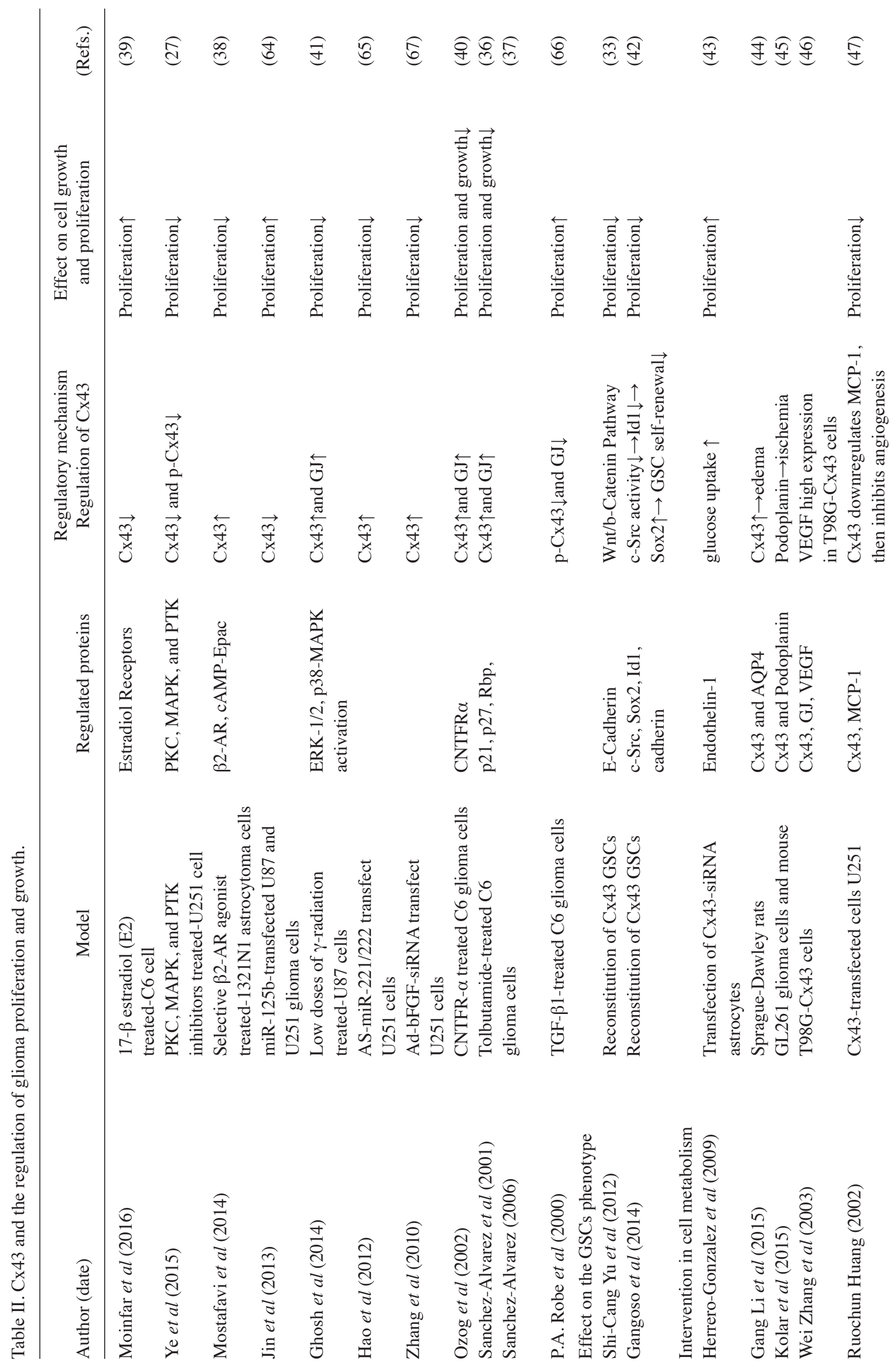




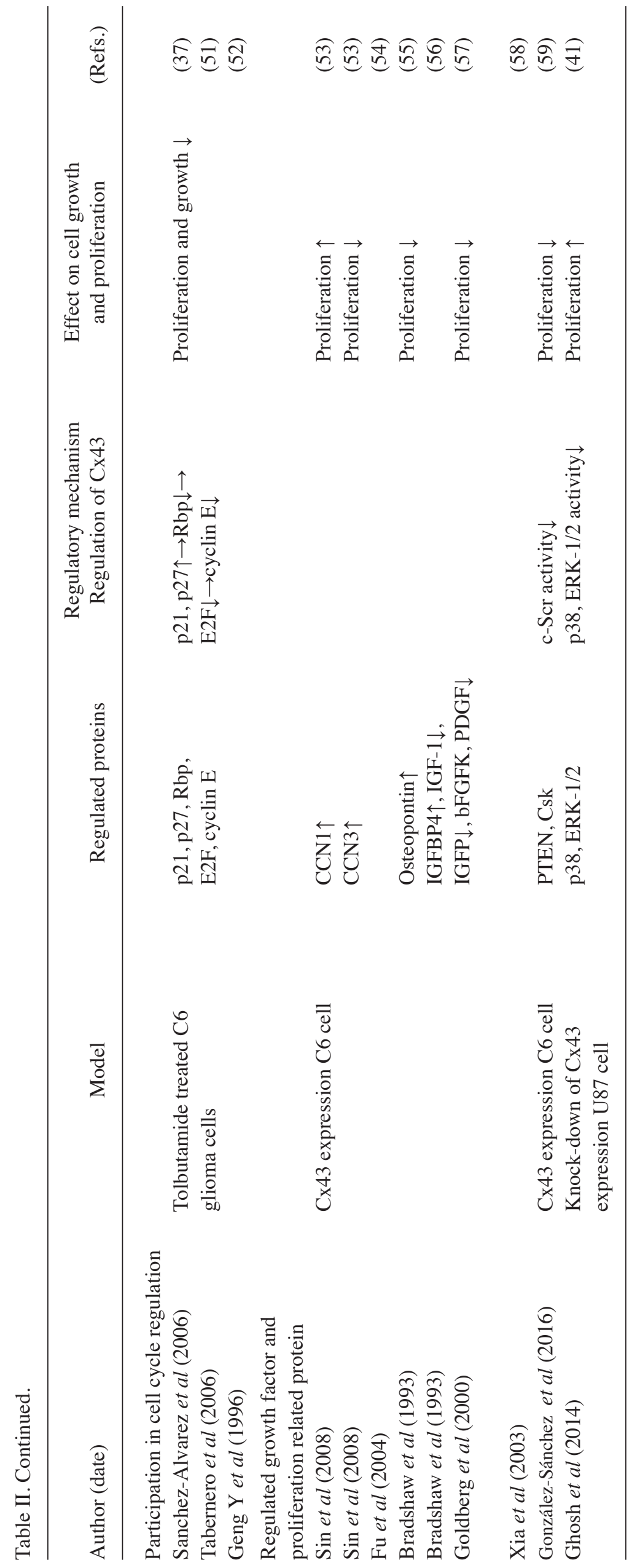




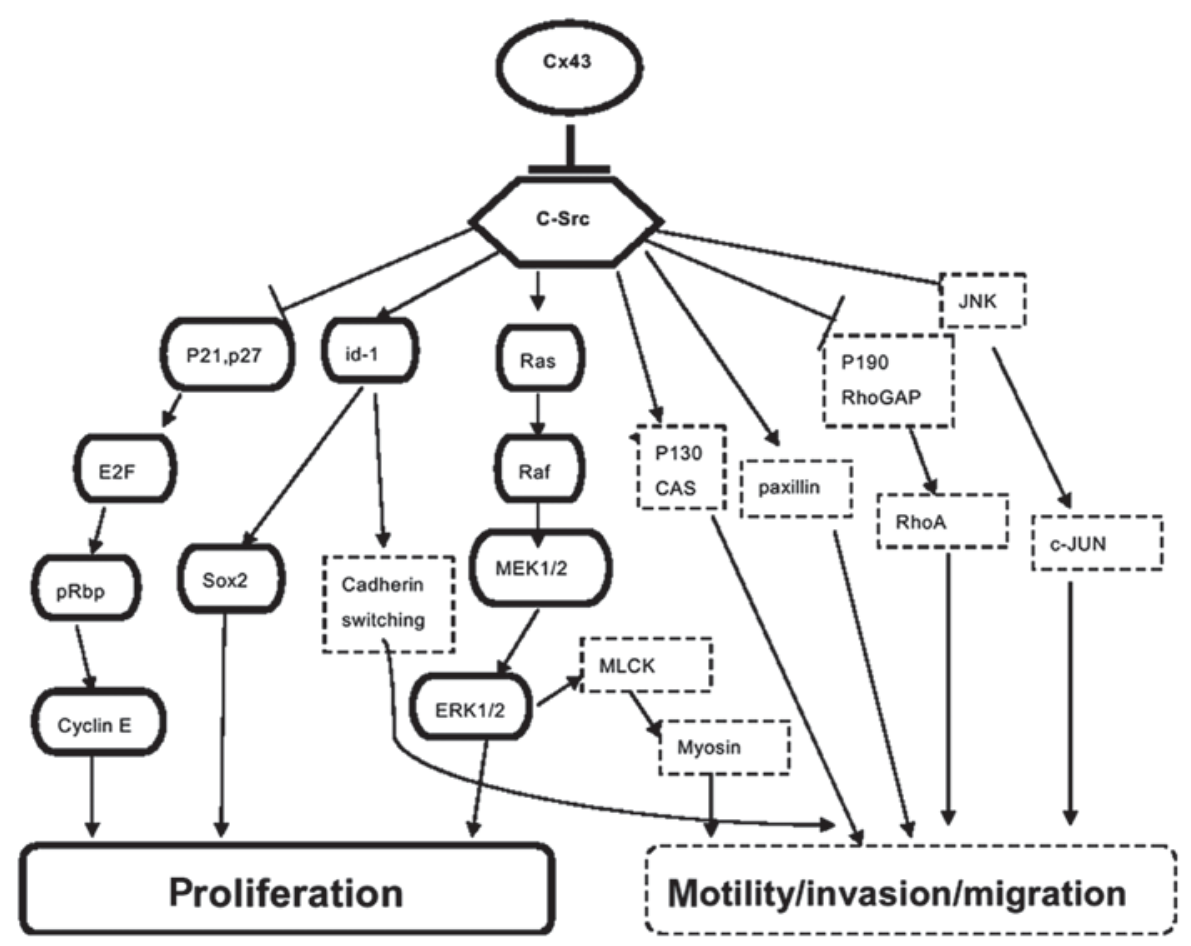

Figure 1. Cx43 interacts with c-Src and inhibits Src activity, sequentially modulating cell polarity, motility and invasion through several signaling pathways. $\mathrm{Cx}$, connexin; c-Src, proto-oncogene tyrosine-protein kinase Src.

transformation of metabolism strategies to enable the cells to survive in a hypoxic tumor microenvironment is a key precondition for the growth and proliferation of GBM cells. Cx43 increases GJ channel and hemi-channel coupling, enabling the exchange of ions, amino acids, metabolites and certain small molecules through the cytomembrane and between astrocytes, together with the extracellular milieu. Notably, that inhibition of GJs or downregulation of $\mathrm{Cx} 43$ expression leads to an increase in glucose uptake (43). Accordingly, this is the main energy substance for glioma cells. Cx43 and its associated GJs are capable of influencing the peritumoral microenvironment of edema (44), ischemia (45) and angiogenesis $(46,47)$, and of interfering with glioma cell metabolism. This may further influence glioma growth and proliferation. Equally, deletion of Cx43 in astrocytes has been observed to inhibit oligodendrocyte precursor cell proliferation by reducing matrix glucose levels (48).

Participation in cell cycle regulation. Cx43 may deter the cell cycle from G1 to S-phase or M-phase $(49,50)$. It is also capable of rebuilding $\mathrm{Cx} 43$ in glioma cells which could delay the progression of cells from G0/G1 to S-phase (37). Cx43 has been observed to increase the expression of p21 and p27, and then weaken retinoblastoma phosphorylation $(\mathrm{pRb})(37,51)$. $\mathrm{pRb}$ phosphorylation promotes the release of E2 transcription factor, which is associated with the expression of cyclin E (52). $\mathrm{Cx} 43$ possibly regulates the glioma cell cycle by decreasing $\mathrm{pRb}$ phosphorylation, subsequently inhibiting cyclin E expression.

Regulation of growth factor and proliferation-associated proteins. Several growth factors (GFs) may also affect the growth and proliferation of cells. Previous research indicates that $\mathrm{Cx} 43$ can regulate certain GF expression levels. For instance, Cx43-transfected glioblastoma cells (U251) downregulate the expression of $\mathrm{MCP}-1$, a factor that can further promote angiogenesis, and then suppress glioma cell proliferation (47). Restored Cx43 expression in C6 glioma cells was also determined as being able to upregulate secretory proteins cysteine-rich angiogenic inducer $(\mathrm{CCN}) 1$ together with $\mathrm{CCN} 3$ expression (53). Notably, over-expression of CCN3 and its interaction with $\mathrm{Cx} 43$ are conducive to a decrease in glioma growth rate. Overexpression of CCN1 exhibits an opposite function $(53,54)$. Similarly, Cx43 transfected to C6 rat glioma cells also regulates the expression of secreted proteins. For instance, it decreases insulin-like growth factor protein, basic fibroblast growth factor, platelet-derived growth factor, insulin-like growth factor 1 and N-methylpurine DNA glycosylase-E8 protein expression levels while increasing CCN3, insulin-like growth factor-binding protein 4 and osteopontin levels (55-58); this is the common outcome of suppressed glioma cell proliferation. Additionally, Cx43 adjusts certain kinase activities to affect the growth and proliferation of cells. For instance, Cx43 recruits phosphatase and tensin homolog and C-terminal Src kinase to inhibit c-Src activity (59). Additionally, c-Src equally combines with the C-terminal of $\mathrm{Cx} 43$ to reduce the oncogenic activity of $\mathrm{c}-\mathrm{Src}(12,42,60)$. Cx43 can also modify the activity of other proliferation-associated proteins, including p38, extracellular signal-regulated kinases-1/2 (44) and zonula occludens (ZO)-1 (12), to affect the proliferation of glioma cells. Suzhi et al (61) noted that $\mathrm{Cx} 43$ could transfer microRNA (miR)-124-3p between coupling cells and improve the antiproliferative ability of miR-124-3p.

Regulation of gene expression. Cx43 regulates gene expression, perhaps as a potential mechanism that influences glioma cell proliferation. However, there are not enough relevant studies 
to support this hypothesis. Dang et al (62) identified that the carboxyl-tail of $\mathrm{Cx} 43$ localizes to the nucleus and inhibits cell growth. Mennecier et al (63) also noted that Cx43 may enter into the nucleus of glioma cell lines. Thus, it may be hypothesized that $\mathrm{Cx} 43$ regulates gene expression directly or indirectly to affect the proliferation and growth of glioma cells.

Controversy of the effect of Cx43 on glioma cell invasion and migration. From the above discussion, it can be deduced that Cx43 is a tumor-suppression factor. However, this valuable role can be weakened by its effects on migration and invasiveness. The majority of the literature reports that $\mathrm{Cx} 43$ enhances glioma invasion $(24,26,68,69)$, while certain studies report the inhibitory action of $\mathrm{Cx} 43$ in glioma invasion and migration $(65,70,71)$. Although $\mathrm{Cx} 43$ is present in a lower expression state in a malignant glioma mass, a high expression of $\mathrm{Cx} 43$ is detected at the plasma membrane of the reactive astrocytes around the peritumor area $(26,28)$, and in tumor cell infiltration and reactive astrocytes. In this area, malignant glioma cells form functional GJ communication between themselves and astrocytes $(28,72)$, establishing a tight cell network (71). This may be the structural basis of the effect of $\mathrm{Cx} 43$ effect the invasion and migration of malignant glioma cells by GJ-dependent and independent mechanisms.

GJ-dependent mechanisms. Reduction of GJ activity has been reported to improve cell migration $(71,73)$. However, more studies report that the overexpression of $\mathrm{Cx} 43$ encourages glioma cell migration and invasion in a GJ channel-dependent manner $(69,72,74)$. Aftab et al (71) demonstrated that downregulation of $\mathrm{Cx} 43$ expression in the U118 human glioma cell line is a way to increase migration by reducing cell-extracellular matrix adhesion, and change the migration pattern from collective to single cell. It was also demonstrated that Cx43-GJ serves more prominent roles in mediating migration and invasion behaviors compared with the C-terminal tail interaction. Functional GJ coupling also contributes to long-range signal transduction, and adjusts the formation of calcium waves $(18,19,41,75)$. Additionally, it transmits signals through second messengers (20). Through these ways, Cx43-GJ may promote the transformation of malignant astrocytes by regulating a glioma-associated signaling pathway. Furthermore, $\mathrm{Cx} 43$ located in lipid raft microdomains can also regulate homocellular and heterocellular GJ communications between cancer and stroma cells, and can control the tumor phenotype $(68,69)$. Consequently, such actions may influence glioma invasion behaviors. Additionally, a Cx43-constructed glioma-astrocyte GJ can modulate glioma invasive behavior by direct transfer of miRs (72). Cx43-GJ is involved in tumor microtube-mediated cell-to-cell communication and influences the motility of glioma cells (75).

GJ-independent mechanisms. Cx43 promotes glioma cell invasion through GJ-reliant mechanisms, which are not always recognized. Sin et al (26) suggested that astrocytic Cx43 may aid glioma cells to detach from the glioma core. However, Cx43 may mediate glioma invasion solely in a GJ-independent manner since the expression of Cx43-T154A has demonstrated no effect on glioma invasion (26). This conclusion contradicts the previously discussed findings in the present review. Certain
Cx43-associated proteins merge with $\mathrm{Cx} 43$ extracellular loops or C-terminal regions to improve adhesive connections or to regulate cytoskeletal dynamics, which alter the structure of Cx43 to facilitate malignant glioma cell invasion and migration by independent mechanisms. A wound healing motility assay indicated that the $\mathrm{C}$-terminal of $\mathrm{Cx} 43$ is required for Cx43-mediated C6 glioma cell motility (24). For instance, Cx43 interacts with ZO-1 protein, which could prevent the cytoplasmic localization and lead to glioma cell invasion $(12,76)$. Cx43 interacts with other cytoskeleton proteins and tight junctions or adherens junctions associated with proteins, including tubulin, cadherins, catenin and actin, to modulate polarity, motility and directional migration of cells (12,24,77,78). In addition, Cx43 interacts with c-Src and inhibits Src activity, sequentially modulating cell polarity, motility and invasion through several signaling pathways (Fig. 1) (12,79,80). In brief, there is no consensus on the effect of $\mathrm{Cx} 43$ on glioma invasion and migration, and the detailed mechanism remains unclear.

\section{Cx43 may promote glioma-associated epileptic discharge}

The association between Cx43/-GJ and epilepsy has widely been studied in the last 20 years. Earlier studies failed to consider that $\mathrm{Cx} 43$ is associated with epilepsy, since expression of $\mathrm{Cx} 43$ had not identified significant differences between epileptogenic and nonepileptogenic tissues, in living tissue assays (81) and animal models (82). Nevertheless, the majority of studies have identified $\mathrm{Cx} 43$ as capable of participating in the genesis and development of certain types of epilepsy. For instance, Cx43 is increasingly expressed in the hippocampus tissue of patients with refractory temporal lobe epilepsy $(83,84)$ and in FCD type IIB (10). Cx43/-GJ were also altered in either lithium pilocarpine-induced epilepsy (84) or in kainic-acid-induced status epilepticus models (85). Notably, the inhibition of the Cx43 GJ with carbenoxolone can shorten the duration of seizures and reduce the amplitude of the seizure discharges (86). In view of the above, $\mathrm{Cx} 43$ may be to be associated with the genesis and development of certain types of epilepsy, in addition to glioma-associated epilepsy.

Glioma-associated epilepsy may be defined as seizure which directly arises from the existence of supratentorial glioma. It is the presenting feature in $\leq 87 \%$ of low-grade gliomas and $\leq 50 \%$ of gliomas overall (87). Epilepsy is usually the initial symptom of glioma patients and a significant factor affecting their post-operative quality of life (88). However, the detailed mechanism of glioma-associated epilepsy remains to be elucidated. It may be a combination of direct mass effects and the change of the tumor microenvironment.

Overall, Cx43 is highly expressed in peritumoral astrocytes (29) which facilitate glioma cells detachment from the tumor core (26). Glioma cells invade the neocortex structure, a special peritumoral region where single neurons are bounded by very few or a single tumor cell (89). This peritumoral region has recently been considered as the basic focus of glioma-associated seizure $(31,90,91)$. GJ changes $(89)$ and the increase of Cx43 expression (30) have been identified in the perilesional tissue of seizures associated with brain tumors. GJ or Cx43-glial coupling may explain glioma-induced epileptogenesis (92). Cx43 and its associated GJ are capable of influencing the peritumoral microenvironment, including edema (44), 
ischemia (45) and angiogenesis $(46,47)$ which may induce epileptic discharge through direct effects of mass. Cx43-GJ is involved in the generation of sharp wave-ripple (34). It propagates neuronal activity through long-range signal transduction and $\mathrm{Ca}^{+}$waves, then promotes a synchronized discharge of neurons (93). Cx43-GJ can also influence seizure discharge by regulating $\mathrm{K}^{+}$redistribution and neuronal energy supply (94). Peritumoral reactive astrocytes can highly express Cx43. Cx43, in this context, may serve a predominant role in the regulation of neurotransmitters, including glutamate. First, Cx43-hem channels/GJ in astrocytes can control glutamate $(95,96)$, release ATP (96) and sustain glutamatergic synaptic efficacy (97). Second, Cx43 knockdown may raise cortical glutamate transporter (GLT)-1 in addition to glutamate aspartate transporter (GLAST) protein expression levels, and control transcription and translation of glial glutamate transporters excitatory amino acid transporter (EAAT)-1 and EAAT-2 (98). Similarly, blocking the gap junction has been reported to suppress transcriptional activity of GLT-1 promoter, but increase GLAST gene transcription (99). The spinal astrocytic Cx43 has also been reported to be capable of activating N-methyl D-aspartate receptors (100) and elemental ionotropic glutamate receptors in the postsynaptic membrane (101). In essence, peritumoral Cx43 high immunoreactivity is mainly on the reactive astrocytes (29), and demonstrates Cx43 to be potentially associated with astrocyte reactivity. A recent study observed that reactive astrocytes not only limit glutamate uptake, but also inhibit the production of gamma-aminobutyric acid. Furthermore, this leads to a loss of inhibition and an increase in neuronal excitability (102). Even so, it can be hypothesized that $\mathrm{Cx} 43$ can possibly promote glioma-associated epileptic discharge through these aforementioned ways. The relevant studies remain scarce, and further studies are required to identify the exact mechanism of $\mathrm{Cx} 43$ in glioma-associated epilepsy.

In summary, the special microenvironment of glioma (tumor cell infiltration and high expression of $\mathrm{Cx} 43$ in reactive astrocytes) may identify why glioma patients present with epilepsy and why they possess a favorable prognosis but are prone to relapses (101). Cx43 also presents in temozolomide resistance and resistance to radiotherapy in glioblastoma cells. The peritumoral region has been considered the basic focus of glioma-associated seizure (31). It is hypothesized that early stage glioma cells highly express $\mathrm{Cx} 43$, and migrate and invade the host parenchyma with a low proliferation index (26).

\section{Facilitating disease diagnosis and therapy}

Investigating biomolecules is useful facilitate disease diagnosis and therapy. The value of $\mathrm{Cx} 43$ in glioma diagnosis and therapy is beginning to be recognized. Abakumova (103) demonstrated that the $\mathrm{Cx} 43$-targeted $\mathrm{T} 1$ contrast agent may efficiently visualize glioma $\mathrm{C} 6$ and its borders in vitro and in vivo. MAbE2Cx43 s was covalently associated with the Phthalosens derivative photosensitizer delivery of fluorescent agents to the glioma tissue. This may be valuable in demonstrating the optimal border and increase the extent of resection due to improved visualization of the glioma (104). Similarly, Cx43/-GJ may help brain tumor cells to interconnect a functional and resistant network (75), which confer temozolomide resistance (105-108) and radiotherapy resistance (75) in glioblastoma cells. The Cx43-antibody MAbE2Cx43 has been demonstrated to be potentially part of a combined therapy for poorly differentiated gliomas (108).

\section{Conclusion}

In regular physiological conditions, $\mathrm{Cx} 43$ is highly expressed in astrocytes. However, this expression is restrained when the malignant transformation of astrocytes and the levels of Cx43 are reduced, along with an increase in the degrees of malignancy in astrocytomas. The association between the expression of Cx43 and degrees of glioma implicates Cx43 as a tumor suppressor, inhibiting glioma cell proliferation. However, the majority of data have indicated that $\mathrm{Cx} 43$ may enhance the motor ability and invasiveness of astrocytic glioma cells, and to facilitate glioma cell separation from the tumor core to the surroundings. This can be interpreted as $\mathrm{Cx} 43$ in the early stages of glioma progression, with a relatively low proliferative index of glioma cells, predisposing glioma cells to migrate and integrate with the host parenchyma (26). Simultaneously, reactive astrocytes and the tumor cell invade into peritumoral tissue comprising the significant surrounding microenvironment, making an ideal environment for epileptic discharge. It is undoubtable that Cx43 or GJ /hemi-channels have a contribution in promoting glioma-associated epileptic discharge through direct mass effects and the change of tumor microenvironment, particularly the effect in excitatory neurotransmitter-glutamate regulation. Notably, $\mathrm{Cx} 43$ expression is considerably upregulated in astrocytes reactive due to tissue damage during surgery. This could promote tumor proliferation, in addition to migration (109), and then facilitate glioma recurrence following resection (110). This can partially explain post-operative epileptic seizures in glioma patients and those with no epilepsy prior to surgery.

Previously published reviews $(12,25)$ have presented the roles of $\mathrm{Cx} 43$ in glioma proliferation in two mechanisms: GJ-dependent and GJ-independent. To the best of our knowledge, the present review was the first to introduce the exact mechanism of these functions and the roles of $\mathrm{Cx} 43$ in glioma-associated epilepsy. Certainly, there are still a number of challenges that require further exploration. If Cx43 is associated with the prognosis of glioma patients, then its potential as a treatment target requires further study. Peritoneal tissue which highly express $\mathrm{Cx} 43$ is involved in the incidence of glioma and is associated with epilepsy; thus, should be explored further.

In conclusion, the roles of $\mathrm{Cx} 43$ in glioma proliferation, in the present review, can be directed to the association between glioma and epilepsy. A number of identifiable challenges in this current review can be the subject of further studies. More importantly, future studies could also aid understanding of any other ways through which Cx43 and other expressions are associated with incidences of glioma and with epilepsy.

\section{References}

1. Louis DN, Ohgaki H, Wiestler OD, Cavenee WK, Burger PC, Jouvet A, Scheithauer BW and Kleihues P: The 2007 WHO classification of tumours of the central nervous system. Acta Neuropathol 114: 97-109, 2007. 
2. Shen F, Wu CX, Yao Y, Peng P, Qin ZY, Wang Y, Zheng Y and Zhou LF: Transition over 35 years in the incidence rates of primary central nervous system tumors in Shanghai, China and histological subtyping based on a single center experience spanning 60 years. Asian Pac J Cancer Prev 14: 7385-7393, 2013.

3. Jiang T, Mao Y, Ma W, Mao Q, You Y, Yang X, Jiang C, Kang C, Li X, Chen L, et al: CGCG clinical practice guidelines for the management of adult diffuse gliomas. Cancer Lett 375: 263-273, 2016.

4. Ceccarelli M, Barthel FP, Malta TM, Sabedot TS, Salama SR, Murray BA, Morozova O, Newton Y, Radenbaugh A, Pagnotta SM, et al: Molecular profiling reveals biologically discrete subsets and pathways of progression in diffuse glioma. Cell 164: 550-563, 2016.

5. Foote MB,Papadopoulos N and Diaz LA Jr: Genetic Classification of Gliomas: Refining Histopathology. Cancer Cell 28: 9-11, 2015.

6. Almad AA, Doreswamy A, Gross SK, Richard JP, Huo Y, Haughey $\mathrm{N}$ and Maragakis NJ: Connexin 43 in astrocytes contributes to motor neuron toxicity in amyotrophic lateral sclerosis. GLIA 64: 1154-1169, 2016.

7. Sharrow AC, Li Y, Micsenyi A, Griswold RD, Wells A, Monga SS and Blair HC: Modulation of osteoblast gap junction connectivity by serum, TNFalpha, and TRAIL. Exp Cell Res 314: 297-308, 2008

8. Giepmans BN: Gap junctions and connexin-interacting proteins. Cardiovasc Res 62: 233-245, 2004.

9. Freitas-Andrade M and Naus CC: Astrocytes in neuroprotection and neurodegeneration: The role of connexin 43 and pannexin1. Neuroscience 323: 207-221, 2016.

10. Garbelli R, Frassoni C, Condorelli DF, Trovato Salinaro A Musso N, Medici V, Tassi L, Bentivoglio M and Spreafico R Expression of connexin 43 in the human epileptic and drug-resistant cerebral cortex. Neurology 76: 895-902, 2011.

11. Almad AA, Doreswamy A, Gross SK, Richard JP, Huo Y, Haughey N and Maragakis NJ: Connexin 43 in Astrocytes Contributes to Motor Neuron Toxicity in Amyotrophic Lateral Sclerosis. Glia 64: 1154-1169, 2016.

12. Tabernero A, Gangoso E, Jaraíz-Rodríguez M and Medina JM: The role of connexin43-Src interaction in astrocytomas: A molecular puzzle. Neuroscience 323: 183-194, 2016.

13. Giaume C, Fromaget C, Aoumari A, Cordier J, Glowinski J and Gros D: Gap junctions in cultured astrocytes: Single-channel currents and characterization of channel-forming protein. Neuron 6: 133-143, 1991.

14. Giaume C, Koulakoff A, Roux L, Holcman D and Rouach N: Astroglial networks: A step further in neuroglial and gliovascular interactions. Nat Rev Neurosci 11: 87-99, 2010.

15. Giaume C, Leybaert L, Naus CC and Sáez JC: Connexin and pannexin hemichannels in brain glial cells: Properties, pharmacology, and roles. Front Pharmacol 4: 88, 2013.

16. Bennett MV, Contreras JE, Bukauskas FF and Sáez JC: New roles for astrocytes: Gap junction hemichannels have something to communicate. Trends Neurosci 26: 610-617, 2003.

17. Nagy JI and Rash JE: Connexins and gap junctions of astrocytes and oligodendrocytes in the CNS. Brain Res Brain Res Rev 32: $29-44,2000$

18. Scemes E: Components of astrocytic intercellular calcium signaling. Mol Neurobiol 22: 167-179, 2000.

19. Van den pol AN, Finkberiner SM and Cornell-Bell AH: Calcium excitability and oscillations in suprachiasmatic nucleus neurons and glia in vitro. J Neurosci 12: 2648-2664, 1992.

20. Mehta PP, Yamamoto M and Rose B. Transcription of the gene for the gap junctional protein connexin43 and expression of functional cell-to-cell channels are regulated by c AMP. Mol Biol Cell 3: 839-850, 1992

21. Giaume C, Tabernero A and Medina JM: Metabolic trafficking through astrocytic gap junctions. Glia 21: 114-123, 1997.

22. Nedergaard M: Direct signaling from astrocytes to neurons in cultures of mammalian brain cells. Science 263: 1768-1771, 1994

23. Zhang W, Nwagwu C, Le DM, Yong VW, Song H and Couldwell WT: Increased invasive capacity of connexin43-overexpressing malignant glioma cells. J Neurosurg 99: 1039-1046, 2003.

24. Bates DC, Sin WC, Aftab Q and Naus CC: Connexin 43 Enhances Glioma Invasion by a Mechanism Involving the Carboxy Terminus. GLIA 55: 1554-1564, 2007.

25. Sin WC, Crespin S and Mesnil M: Opposing roles of connexin 43 in glioma progression. Biochim Biophys Acta 1818: 2058-2067, 2012.

26. Sin WC, Aftab Q, Bechberger JF, Leung JH, Chen H and Naus CC: Astrocytes promote glioma invasion via the gap junction protein connexin43. Oncogene 35: 1504-1516, 2016.
27. Ye XY, Jiang QH, Hong T, Zhang ZY, Yang RJ, Huang JQ, Hu K and Peng YP: Altered expression of connexin43 and phosphorylation connexin43 in glioma tumors. Int J Clin Exp Pathol 8: 4296-4306, 2015

28. Crespin S, Fromont G, Wager M, Levillain P, Cronier L, Monvoisin A, Defamie N and Mesnil M: Expression of a gap junction protein, connexin43, in a large panel of human gliomas: New insights. Cancer Med 5: 1742-1752, 2016.

29. Kolar K, Freitas-Andrade M, Bechberger JF, Krishnan H, Goldberg GS, Naus CC and Sin WC: Podoplanin: A marker for reactive gliosis in gliomas and brain injury. J Neuropathol Exp Neurol 74: 64-74, 2015.

30. Aronica E, Gorter JA, Jansen GH, Leenstra S, Yankaya B and Troost D: Expression of connexin 43 and connexin 32 gap-junction proteins in epilepsy-associated brain tumors and in the perilesional epileptic cortex. Acta Neuropathol 101: 449-459, 2001.

31. Pallud J, Le Van Quyen M, Bielle F, Pellegrino C, Varlet P, Cresto N, Baulac M, Duyckaerts C, Kourdougli N, Chazal G, et al: Cortical GABAergic excitation contributes to epileptic activities around human glioma. Sci Transl Med 6: 244ra89, 2014.

32. Hitomi M, Deleyrolle LP, Mulkearns-Hubert EE, Jarrar A, Li M, Sinyuk M, Otvos B, Brunet S, Flavahan WA, Hubert CG, et al: Differential connexin function enhances self-renewal in glioblastoma. Cell Rep 11: 1031-1042, 2015.

33. Yu SC, Xiao HL, Jiang XF, Wang QL, Li Y, Yang XJ, Ping YF, Duan JJ, Jiang JY, Ye XZ, et al: Connexin 43 reverses malignant phenotypes of glioma stem cells by modulating E-cadherin. Stem Cell 30: 108-120, 2012.

34. Moinfar Z, Dambach H and Faustmann PM: Influence of drugs on gap junctions in glioma cell lines and primary astrocytes in vitro. Front Physiol 5: 186, 2014.

35. Naus CC and Laird DW: Implications and challenges of connexin connections to cancer. Nat Rev Cancer 10: 435-441, 2010.

36. Sánchez-Alvarez R, Tabernero A, Sánchez-Abarca LI, Orfao A, Giaume C and Medina JM: Proliferation of C6 glioma cells is blunted by the increase in gap junction communication caused by tolbutamide, FEBS Lett 509: 202-206, 2001.

37. Sánchez-Alvarez R, Paíno T, Herrero-González S, Medina JM and Tabernero A: Tolbutamide reduces glioma cell proliferation by increasing connexin43, which promotes the up-regulation of p21 and p27 and subsequent changes in retinoblastoma phosphorylation. Glia 54: 125-134, 2006.

38. Mostafavi H, Khaksarian M, Joghataei MT, Soleimani M, Hassanzadeh G, Eftekhari S, Soleimani M, Mousavizadeh K, Estiri H, Ahmadi S and Hadjighassem MR: Selective $\beta 2$ adrenergic agonist increases Cx43 and miR-451 expression via cAMP-Epac. Mol Med Rep 9: 2405-2410, 2014

39. Moinfar Z, Dambach H, Schoenebeck B, Förster E, Prochnow N and Faustmann PM: Estradiol receptors regulate differential connexin 43 expression in F98 and C6 glioma cell lines. PLoS One 11: e0150007, 2016.

40. Ozog MA, Bechberger JF and Naus CC: Ciliary neurotrophic factor (CNTF) in combination with its soluble receptor (CNTFRalpha) increases connexin43 expression and suppresses growth of C6 glioma cells. Cancer Res 62: 3544-3548, 2002.

41. Ghosh S, Kumar A, Tripathi RP and Chandna S: Connexin-43 regulates p38-mediated cell migration and invasion induced selectively in tumour cells by low doses of $\gamma$-radiation in an ERK-1/2-independent manner. Carcinogenesis 35: 383-395, 2014.

42. Gangoso E, Thirant C, Chneiweiss H, Medina JM and Tabernero A: A cell-penetrating peptide based on the interaction between c-Src and connexin 43 reverses glioma stem cell phenotype. Cell Death Dis 5: e1023, 2014

43. Herrero-González S, Valle-Casuso JC, Sánchez-Alvarez R, Giaume C, Medina JM and Tabernero A: Connexin43 is involved in the effect of endothelin-1 on astrocyte proliferation and glucose uptake. Glia 57: 222-233, 2009.

44. Li G, Liu X, Liu Z and Su Z: Interactions of connexin 43 and aquaporin- 4 in the formation of glioma-induced brain edema, Mol Med Rep 11: 1188-1194, 2015

45. Kolar K, Freitas-Andrade M, Bechberger JF, Krishnan H, Goldberg GS, Naus CC and Sin WC: Podoplanin: A marker for reactive gliosis in gliomas and brain injury. J Neuropathol Exp Neurol 74: 64-74, 2015.

46. Zhang W, DeMattia JA, Song $\mathrm{H}$ and Couldwell WT: Communication between malignant glioma cells and vascular endothelial cells through gap junctions. J Neurosurg 98: 846-853, 2003. 
47. Huang R, Lin Y, Wang CC, Gano J, Lin B, Shi Q, Boynton A, Burke J and Huang RP: Connexin 43 suppresses human glioblastoma cell growth by down-regulation of monocyte chemotactic protein 1, as discovered using protein array technology. Cancer Res 62: 2806-2812, 2002

48. Niu J, Li T, Yi C, Huang N, Koulakoff A, Weng C, Li C, Zhao CJ, Giaume C and Xiao L: Connexin-based channels contribute to metabolic pathways in the oligodendroglial lineage. J Cell Sci 129: 1902-1914, 2016

49. Zhang YW, Nakayama K, Nakayama K and Morita I: A novel route for connexin 43 to inhibit cell proliferation: Negative regulation of S-phase kinase-associated protein (Skp 2). Cancer Res 63: 1623-1630, 2003

50. Kamei J, Toyofuku T and Hori M: Negative regulation of p21 by beta-catenin/TCF signaling: A novel mechanism by which cell adhesion molecules regulate cell proliferation. Biochem Biophys Res Commun 312: 380-387, 2003.

51. Tabernero A, Sánchez-Alvarez R and Medina JM: Increased levels of cyclins D1 and D3 after inhibition of gap junctional communication in astrocytes. J Neurochem 96: 973-982, 2006.

52. Geng Y, Eaton EN, Picón M, Roberts JM, Lundberg AS Gifford A, Sardet C and Weinberg RA: Regulation of cyclin E transcription by E2Fs and retinoblastoma protein. Oncogene 12: 1173-1180, 1996

53. Sin WC, Bechberger JF, Rushlow WJ and Naus CC: Dose-dependent differential upregulation of CCN1/Cyr61 and $\mathrm{CCN} 3 / \mathrm{NOV}$ by the gap junction protein connexin43 in glioma cells. J Cell Biochem 103: 1772-1782, 2008.

54. Fu CT, Bechberger JF, Ozog MA, Perbal B and Naus CC: CCN3 (NOV) interacts with connexin43 in C6 glioma cells: Possible mechanism of connexin-mediated growth suppression. J Biol Chem 279: 36943-36950, 2004

55. Bradshaw SL, Naus CC, Zhu D, Kidder GM, D'Ercole AJ and Han VK: Alterations in the synthesis of insulin-like growth factor binding proteins and insulin-like growth factors in rat C6 glioma cells transfected with a gap junction connexin43 cDNA. Regul Pept 48: 99-112, 1993.

56. Bradshaw SL, Naus CC, Zhu D, Kidder GM and Han VK: Insulin-like growth factor binding protein- 4 gene expression is induced by transfection of gap junction connexin 43 gene in a C6 glioma cell line. Growth Regul 3: 26-29, 1993

57. Goldberg GS, Bechberger JF, Tajima Y, Merritt M, Omori Y, Gawinowicz MA, Narayanan R, Tan Y, Sanai Y, Yamasaki H, et al: Connexin43 suppresses MFG-E8 while inducing contact growth inhibition of glioma cells. Cancer Res 60: 6018-6026, 2000.

58. Xia ZB, Pu PY, Huang Q, You YP, Wang GX and Wang CY: Preliminary study on the mechanism of connexin 43 gene transfection in the control of glioma cell proliferation. Zhonghua Zhong Liu Za Zhi 25: 4-8, 2003 (In Chinese).

59. González-Sánchez A, Jaraíz-Rodríguez M, Domínguez-Prieto M Herrero-González S, Medina JM and Tabernero A: Connexin43 recruits PTEN and Csk to inhibit c-Src activity in glioma cells and astrocytes. Oncotarget 7: 49819-49833, 2016.

60. Herrero-González S, Gangoso E, Giaume C, Naus CC, Medina JM and Tabernero A: Connexin43 inhibits the oncogenic activity of c-Src in C6 glioma cells. Oncogene 29: 5712-5723, 2010.

61. Suzhi Z, Liang T, Yuexia P, Lucy L, Xiaoting H, Yuan Z and Qin W: Gap junctions enhance the antiproliferative effect of microRNA-124-3p in glioblastoma cells. J Cell Physiol 230: 2476-2488, 2015

62. Dang X, Doble BW and Kardami E: The carboxy-tail of connexin-43 localizes to the nucleus and inhibits cell growth Mol Cell Biochem 242: 1-2, 2003.

63. Mennecier G, Derangeon M, Coronas V, Hervé JC and Mesnil M: Aberrant expression and localization of connexin43 and connexin30 in a rat glioma cell line. Mol Carcinog 47: 391-401, 2008.

64. Jin Z, Xu S, Yu H, Yang B, Zhao H and Zhao G: miR-125b inhibits connexin43 and Promotes glioma growth. Cell Mol Neurobiol 33: 1143-1148, 2013

65. Hao J, Zhang C, Zhang A, Wang K, Jia Z, Wang G, Han L, Kang C and Pu P: miR-221/222 is the regulator of Cx43 expression in human glioblastoma cells, Oncol Rep 27: 1504-1510, 2012.

66. Robe PA, Rogister B, Merville MP and Bours V: Growth regulation of astrocytes and C6 cells by TGFbeta1: Correlation with gap junctions. NeuroReport 11: 2837-2841, 2000

67. Zhang B, Feng $X$, Wang J, Xu X, Liu $H$ and Lin $N$ : Adenovirus-mediated delivery of bFGF small interfering RNA increases levels of connexin 43 in the glioma cell line, U251. J Exp Clin Cancer Res 29: 3, 2010.
68. Zhang W, Nwagwu C, Le DM, Yong VW, Song H and Couldwell WT: Increased invasive capacity of connexin43-overexpressing malignant glioma cells. J Neurosurg 99: 1039-1046, 2003.

69. Strale PO, Clarhaut J, Lamiche C, Cronier L, Mesnil M and Defamie N: Down-regulation of Connexin43 expression reveals the involvement of caveolin-1 containing lipid rafts in human U251 glioblastoma cell invasion. Mol Carcinog 51: 845-860, 2012.

70. Qin LJ, Jia YS, Zhang YB and Wang YH: Cyclooxygenase inhibitor induces the upregulation of connexin-43 expression in C6 glioma cells. Biomed Rep 4: 444-448, 2016.

71. Aftab Q, Sin WC and Naus C: Reduction in gap junction intercellular communication promotes glioma migration. Oncotarget 6 : 11447-11464, 2015

72. Hong X, Sin WC, Harris AL and Naus CC: Gap junctions modulate glioma invasion by direct transfer of microRNA. Oncotarget 6: 15566-15577, 2015.

73. McDonough WS, Johansson A, Joffee H, Giese A and Berens ME: Gap junction intercellular communication in gliomas is inversely related to cell motility. Int J Dev Neurosci 17: 601-611, 1999.

74. Osswald M, Jung E, Sahm F, Solecki G, Venkataramani V, Blaes J, Weil S, Horstmann H, Wiestler B, Syed M, et al: Brain tumour cells interconnect to a functional and resistant network. Nature 528: 93-98, 2015.

75. Reichert M, Müller T and Hunziker W: The PDZ domains of zonula occludens-1 induce an epithelial to mesenchymal transition of Madin-Darby canine kidney I cells. Evidence for a role of beta-catenin/Tcf/Lef signaling. J Biol Chem 275: 9492-9500, 2000.

76. Lin JH, Takano T, Cotrina ML, Arcuino G, Kang J, Liu S, Gao Q, Jiang L, Li F, Lichtenberg-Frate H, et al: Connexin 43 enhances the adhesivity and mediates the invasion of malignant glioma cells. J Neurosci 22: 4302-4311, 2002.

77. Reszec J, Szkudlarek M, Hermanowicz A, Bernaczyk PS Mariak Z and Chyczewski L: N-cadherin, beta-catenin and connexin 43 expression in astrocytic tumours of various grades. Histol Histopathol 30: 361-371, 2015.

78. Kirschstein T and Köhling R: Animal models of tumour-associated epilepsy. J Neurosci Methods 260: 109-117, 2016.

79. Patel A, Sabbineni H, Clarke A and Somanath PR: Novel roles of Src in cancer cell epithelial-to-mesenchymal transition, vascular permeability, microinvasion and metastasis. Life Sci 157: 52-61, 2016.

80. Elisevich K, Rempel SA, Smith BJ and Edvardsen K: Hippocampal connexin 43 expression in human complex partial seizure disorder. Exp Neurol 145: 154-164, 1997.

81. Senner V, Köhling R, Püttmann-Cyrus S, Straub H, Paulus W and Speckmann EJ: A new neurophysiological/neuropathological ex vivo model localizes the origin of glioma-associated epileptogenesis in the invasion area. Acta Neuropathol 107: 1-7, 2004.

82. Das A, Wallace GC IV, Holmes C, McDowell ML, Smith JA, Marshall JD, Bonilha L, Edwards JC, Glazier SS, Ray SK, et al: Hippocampal tissue of patients with refractory temporal lobe epilepsy is associated with astrocyte activation, inflammation, and altered expression of channels and receptors. Neuroscience 220: 237-246, 2012.

83. Fonseca CG, Green CR and Nicholson LF: Upregulation in astrocytic connexin 43 gap junction levels may exacerbate generalized seizures in mesial temporal lobe epilepsy. Brain Res 929: 105-116, 2002

84. Su M and Tong XX: Astrocytic gap junction in the hippocampus of rats with lithium pilocarpine-induced epilepsy. Nan Fang Yi Ke Da Xue Xue Bao 30: 2738-2741, 2010 (In Chinese).

85. Takahashi DK, Vargas JR and Wilcox KS: Increased coupling and altered glutamate transport currents in astrocytes following kainic-acid-induced status epilepticus. Neurobiol Dis 40: 573-585, 2010.

86. Oliveira R, Christov C, Guillamo JS, de Boüard S, Palfi S, Venance L, Tardy M and Peschanski M: Contribution of gap junctional communication between tumor cells and astroglia to the invasion of the brain parenchyma by human glioblastomas. BMC Cell Biol 6: 7, 2005.

87. Liubinas SV, O'Brien TJ, Moffat BM, Drummond KJ, Morokoff AP and Kaye AH: Tumour associated epilepsy and glutamate excitotoxicity in patients with gliomas. J Clin Neurosci 21: 899-908, 2014.

88. Armstrong TS, Grant R, Gilbert MR, Lee JW and Norden AD: Epilepsy in glioma patients: Mechanisms, management, and impact of anticonvulsant therapy. Neuro Oncol 18: 779-789, 2016. 
89. Elisevich K, Rempel SA, Smith B and Allar N: Connexin 43 mRNA expression in two experimental models of epilepsy. Mol Chem Neuropathol 32: 75-88, 1997.

90. Köhling R, Senner V, Paulus W and Speckmann EJ: Epileptiform activity preferentially arises outside tumor invasion zone in glioma xenotransplants. Neurobiol Dis 22: 64-75, 2006.

91. Buckingham SC, Campbell SL, Haas BR, Montana V, Robel S, Ogunrinu $\mathrm{T}$ and Sontheimer H: Glutamate release by primary brain tumors induces epileptic activity. Nat Med 17: 1269-1274, 2011.

92.Kim LC, Song L and Haura EB: Src kinases as therapeutic targets for cancer. Nat Rev Clin Oncol 6: 587-595, 2009.

93. Mylvaganam S, Ramani M, Krawczyk M and Carlen PL: Roles of gap junctions, connexins, and pannexins in epilepsy. Front Physiol 5: 172, 2014

94.Kékesi O, Ioja E, Szabó Z, Kardos J and Héja L: Recurrent seizure-like events are associated with coupled astroglia synchronization. Front Cell Neurosci 9: 215, 2015.

95. Jiang S, Wang YQ, Xu CF, Li YN, Guo R and Li L: Involvement of connexin43 in the infrasonic noise-induced glutamate release by cultured astrocytes. Neurochem Res 39: 833-842, 2014.

96. Wei H, Deng F, Chen Y, Qin Y, Hao Y and Guo X: Ultrafine carbon black induces glutamate and ATP release by activating connexin and pannexin hemichannels in cultured astrocytes. Toxicology 323: 32-41, 2014.

97. Chever O, Pannasch U, Ezan P and Rouach N: Astroglial connexin 43 sustains glutamatergic synaptic efficacy. Philos Trans R Soc Lond B Biol Sci 369: 20130596, 2014.

98. Unger T, Bette S, Zhang J, Theis $M$ and Engele J: Connexin-deficiency affects expression levels of glial glutamate transporters within the cerebrum. Neurosci Lett 506: 12-16, 2012.

99. Figiel M, Allritz C, Lehmann C and Engele J: Gap junctional control of glial glutamate transporter expression. Mol Cel Neurosci 35: 130-137, 2007.

100. Shen N, Mo LQ, Hu F, Chen PX, Guo RX and Feng JQ: A novel role of spinal astrocytic connexin 43: Mediating morphine antinociceptive tolerance by activation of NMDA receptors and inhibition of glutamate transporter-1 in rats. CNS Neurosci Ther 20: 728-736. 2014.
101. Huberfeld G and Vecht CJ: Seizures and gliomas--towards a single therapeutic approach. Nat Rev Neurol 12: 204-216, 2016.

102. Robel S and Sontheimer H: Glia as drivers of abnormal neuronal activity. Nat Neurosci 19: 28-33, 2016.

103. Abakumova T, Abakumov M, Shein S, Chelushkin P, Bychkov D, Mukhin V, Yusubalieva G, Grinenko N, Kabanov A, Nukolova N and Chekhonin V: Connexin 43-targeted T1 contrast agent for MRI, diagnosis of glioma. Contrast Media Mol Imaging 11: $15-23,2016$

104. Iusubalieva GM, Zorkina Ia A, Baklaushev VP, Gurina OI, Goriă̌nov SA, Aleksandrova EV, Zhukov VIu, Savel'eva TA, Potapov AA and Chekhonin VP: Connexin-43 antibodies In Intraoperative diagnosis of experimental poorly differentiated gliomas. Zh Vopr Neirokhir Im N N Burdenko 78: 3-13, 2014 (In Russian).

105. Gielen PR, Aftab Q, Ma N, Chen VC, Hong X, Lozinsky S, Naus CC and Sin WC: Connexin 43 confers Temozolomide resistance in human glioma cells by modulating the mitochondrial apoptosis pathway. Neuropharmacology 75: 539-548, 2013

106. Murphy SF, Varghese RT, Lamouille S, Guo S, Pridham KJ, Kanabur P, Osimani AM, Sharma S, Jourdan J, Rodgers CM, et al: Connexin 43 inhibition sensitizes chemoresistant glioblastoma cells to temozolomide. Cancer Res 76: 139-149, 2016.

107. Munoz JL, Rodriguez-Cruz V, Greco SJ, Ramkissoon SH, Ligon KL and Rameshwar P: Temozolomide resistance in glioblastoma cells occurs partly through epidermal growth factor receptor-mediated induction of connexin 43. Cell Death Dis 5: e1145, 2014.

108. Yusubalieva GM, Baklaushev VP, Gurina OI, Zorkina YA, Gubskii IL, Kobyakov GL, Golanov AV, Goryainov SA, Gorlachev GE, Konovalov AN, et al: Treatment of poorly differentiated glioma using a combination of monoclonal antibodies to extracellular connexin-43 fragment, temozolomide, and radiotherapy. Bull Exp Biol Med 157: 510-515, 2014.

109. Okolie O, Bago JR, Schmid RS, Irvin DM, Bash RE, Miller CR and Hingtgen SD: Reactive astrocytes potentiate tumor aggressiveness in a murine glioma resection and recurrence model. Neuro Oncol 18: 1622-1633, 2016.

110. Theodoric N, Bechberger JF, Naus CC and Sin WC: Role of gap junction protein Connexin 43 in astrogliosis induced by brain injury. PLoS One 7: e47311, 2012. 